\title{
The relationship between urologic cancer outcomes and national Human Development Index: trend from 2012 to 2018
}

\section{Nan Zhang}

the second affiliated hospital, Zhejiang University School of Medicine https://orcid.org/0000-00016741-9621

\section{Hua Mu}

the first affiliated hospital, Dalian Medical University

Yan-rou Jiang

the second affiliated hospital, Zhejiang University School of Medicine

Shi-geng Zhang ( $\sim$ zsg710728@zju.edu.cn )

https://orcid.org/0000-0002-2808-1338

\section{Research article}

Keywords: urologic cancer, Human Development Index, incidence, mortality, survival

Posted Date: September 23rd, 2019

DOI: https://doi.org/10.21203/rs.2.14786/v1

License: (9) This work is licensed under a Creative Commons Attribution 4.0 International License. Read Full License 


\section{Abstract}

Objectives To describe the influence of the socioeconomic development on worldwide age-standardized incidence and mortality rates, as well as mortality-to-incidence ratio (MIR) and 5-year net survival of urologic cancer patients from 2012 to 2018 . Methods The HDI values were obtained from the United Nations Development Programme, data on age-standardized incidence/mortality rates of prostate, bladder and kidney cancer were retrieved from the GLOBOCAN database, 5-year net survival was provided by the CONCORD-3 program. We then evaluated the association between incidence/MIR/survival and $\mathrm{HDI}$, with a focus on geographic variability as well as temporal patterns during the last 6 years. Results Urologic cancer incidence rates were positively correlated with HDIs, and MIRs were negatively correlated with HDIs. Prostate cancer survival also correlated positively with HDIs, solidly confirming the interrelation among cancer indicators and socioeconomic factors. Most countries experienced incidence decline over the most recent 6 years, and a substantial reduction in MIR was observed. Survival rates of prostate cancer have simultaneously improved. Conclusion Development has a prominent influence on urologic cancer outcomes. HDI values are significantly correlated with cancer incidence, MIR and survival rates. HDI values have risen along with increased incidence and improved outcomes of urologic caner in recent years.

\section{Background}

With the growing and aging population, cancer has been expected to rank as the leading cause of death and the most important barrier to increasing life expectancy across the world [1]. Urologists are the front line for the diagnosis and treatment of urologic malignancies, mainly including prostate, bladder, and kidney cancer [2]. According to Global Cancer Statistics 2018, bladder, prostate and kidney cancers have ranked the $3^{\text {rd }}, 10^{\text {th }}$ and $14^{\text {th }}$ most common tumors worldwide, respectively [1]. The global composition of urologic cancer patients has been continuously evolving due to multiple forces [3,2,1,4-9].

Socioeconomic development is closely interconnected with public health [10]. Human Development Index $(\mathrm{HDI})$ is the gold standard for the comparison of socioeconomic development, quantified by the composite measures of health, education, and economy [11]. Multiple studies had demonstrated that cancer outcomes were related with HDI $[12,13]$. Some identified there was a negative correlation between standardized mortality rates and HDI [14] but others verified no significant correlation [15]. Furthermore, the different urologic cancer profiles in individual countries signify that marked geographic diversity still exists nowadays. But the global distribution and transition of urologic neoplasms under social development and medical advances in recent years are still not clarified.

This study aims to describe the influence of HDI values on global urologic cancer burden and outcomes, including incidence rates, mortality-to-incidence ratio (MIR) and 5-year survival rates, with a focus on the transition for the years 2012 through 2018.

\section{Methods}




\subsection{Data sources}

The incidence and mortality estimates of urologic cancer were originally extracted from the GLOBOCAN database (http://gco.iarc.fr) maintained by the International Agency for Research on Cancer (IARC). Data within 186 countries in 2018 and 175 countries in 2012 were incorporated. All indicators were presented in forms of age-standardized rates (ASRs) per 100,000 person-years. The ASRs were calculated according to the world standard population, allowing comparisons between populations without being influenced by differences in their age structures $[1,16]$.

HDI data for United Nations members during 2012-2018 period were available in the United Nations Development Programme (UNDP) database (http://hdr.undp.org/en/statistics). We further collected the 5year net survival estimates of patients diagnosed with prostate cancer from the CONCORD-3 report which corresponded with patient status in year 2012 and 2018 [17]. Net survival is the cumulative probability of surviving up to a given time since diagnosis (e.g., 5 years) after correcting for other causes of death (background mortality) [17].

\subsection{Statistical analysis}

With the obtained incidence and mortality rates, we calculated the urologic cancer mortality-to-incidence ratio (MIR) (ie., cancer deaths divided by incident cancer cases). Extreme values $(0,1$ or $>1)$ were considered abnormal and were excluded from the analysis. To examine patterns in the MIR of urologic cancer by levels of socioeconomic development, we correlated the MIRs to the corresponding HDIs via linear and nonlinear regression. Linear regression fit was conducted to identify the existence of correlation. Correlation was established with a significant $p$ value in the nonparametric Spearman correlation test. Nonlinear regression was based on a modified "dose-to-response" model using the formula , $\mathrm{HDI}_{50}$ refers to the half-maximal controlled $\mathrm{HDI}$ (equivalent to the HDI value at half-maximal $\mathrm{MIR}$ ) and slope is a parameter indicating the steepness of the fitted curve. MIRs comparison among 4-tier HDI groups was analyzed via One-way ANOVA followed by Tukey-Kramer post hoc tests. We further examined the correlation of national incidence rates and 5-year net survival estimates with corresponding $\mathrm{HDI}$, separately. In order to determine the effects of socioeconomic transitions on urologic cancer outcomes, we further compared the age-standardized MIR or 5-year net survival estimates in the year of 2012 and 2018 (paired t-test). A $p$ value less than 0.05 was considered statistically significant. Statistical analysis and plotting were performed using Prism 7 (GraphPad, San Diego, CA).

Global geographical maps were depicted by TileMill (a GitHub software maintained by MapBox, Washington, DC), with map data sources from the Natural Earth database rendered by the Mapnik Library (https://mapnik.org/).

\section{Results}

\subsection{Overview of current global urologic cancer epidemiology}


Development levels of countries were classified into 4 classes according to HDI values by the UNDP (Fig. 1a). The global age-standardized incidence and mortality rates of prostate, bladder and kidney cancer in 2018 were presented separately (Fig. S1a-f). Mortality-to-incidence ratios (MIRs) were calculated and their global distribution was depicted in the form of world maps (Fig. 1b-d).

Prostate cancer ranked as the second most frequent cancer in men. The top countries with the highest incidence rates of prostate cancer were all in very-high HDI group (Fig. S1a), including Europe (e.g., Ireland, Estonia, Norway, Sweden, France, United Kingdom, etc.), North America (United States), Australia/ New Zealand, and Barbados. However, mortality rates did not follow those of incidence. The highest mortality rates fell mainly in countries with lower HDI (Fig. S1b), including the Caribbean and Africa. The lowest MIRs were achieved in highly developed countries (Fig. 1b), such as France, Ireland, Italy, Spain, United States. Whereas low-to-medium HDI countries owned the highest MIRs (Afghanistan, Guinea, Pakistan, Liberia). Similarly, bladder and kidney cancer was most common to happen in high-to-very high HDI regions (Fig. S1c, 1e), especially European countries. However, the top 10 countries with highest MIRs of bladder cancer were all from low-HDI group in Africa (Fig. 1c, 1d). The lowest MIR was from very-high HDI group.

\subsection{The correlation between urologic cancer MIR and national HDI}

The global MIR of prostate, bladder and kidney cancer in 2018 was $0.358,0.251$, and 0.410 , respectively (Fig. 1b-d). We found that as the level of national HDI increased, the corresponding urologic cancer MIR was relatively lower, with strong correlation $(r<0, p<0.0001)$. We also applied nonlinear regression analysis on data, verifying the existence of a "dose-to-response" inhibitory effect between HDI values and MIRs (Fig. 2a-b, d-e, $\mathbf{g}-\mathbf{h})$. The HDI values at half maximal MIR ( $\left.\mathrm{HDI}_{50}\right)$ of prostate, bladder and kidney cancer in 2018 was $0.639,0.704$ and 0.736 , respectively.

We further compared the MIRs of urologic cancer among 4-tier HDI groups and clarified the persistent disparities associated with HDI levels ( $p<0.0001$, One-way ANOVA). Take prostate cancer in 2018 for example, the mean MIR in very-high HDI countries (0.224) was significantly lower than that in high(0.424), medium- (0.522), or low- (0.641) HDI countries ( $p<0.0001$, Tukey's post hoc test; Fig. $2 \mathrm{c}$ ). Similar results were obtained in other cancer sites (bladder, kidney) as well as data in $2012(p<0.0001$, Tukey's post hoc test; Fig. 2f, i).

\subsection{Association between incidence rates of urologic cancer and HDI}

Since the fact that urologic cancers tended to happen more in high-to-very high-HDI countries, we also applied correlation analysis on the association between incidence rates and HDI. It was demonstrated that national incidence rates in urologic cancer all had strong correlation with corresponding HDIs via linear regression ( $r>0, p<0.0001$; Fig. 3a-c).

\subsection{The impact of HDI on 5-year survival of prostate cancer}


The 5-year net survival rates were available in 57 countries for prostate cancer in CONCORD-3 program (Fig. 4a). Similar to MIRs, patients diagnosed during 2010-2014 from very-high-HDI countries like Cyprus (99.2\%), United States (98.1\%) and Israel (95.6\%) topped in survival rates. While countries with limited developments, like South Africa (37.8\%), India (44.3\%) and Nigeria (58.7\%), fell far behind other regions. Cross-national analysis demonstrated that survival rates of patients diagnosed in 2010-2014 correlated positively with HDI values via linear regression ( $r=1.084, p<0.0001$; Fig. 4b). Accordingly, the survival rates correlated inversely with national MIR $(r=-0.730, p<0.0001$; Fig. 4c).

\subsection{Temporal transition of urologic cancer burdens and outcomes fromm 2012 to 2018}

\subsubsection{Prostate cancer}

Incidence and mortality rates of prostate cancer have risen considerably since the end of last century [2]. Nevertheless, it should be noted that between 2012 and 2018, new prostate cases decreased from 1276706 to 1111689 , and fell from 358989 to 307417 in deaths. In general, the MIR of prostate cancer did not change much during the past 6 years $(0.251$ vs 0.259$)$. We plotted national HDIs and MIRs in 2018 and 2012 together and noticed similar distributions (Fig. 5a). Notably, there is an evident change that linear regression line has shifted to the lower-left direction from 2012 to 2018 , most obviously among countries with lower HDIs. Furthermore, within both low- and medium- HDI groups, the national MIRs in 2018 decreased significantly in comparison to the 2012 data $(p<0.0001$ for both groups; Fig. 2c). In high HDI groups, there was only decreasing tendency without significance $(0.424$ vs $0.460, p>$ 0.05 ; Fig. 2c). The survival rates generally increased, with only 7 out of 57 countries dropped more than $1 \%(p<0.05)$ (Fig. 5b; Table 1).

\subsubsection{Bladder cancer}

New bladder cancer diagnoses shrank nearly a quarter between 2012 and 2018 (549 393 vs 429 793). It is remarkable that MIR of bladder cancer in 2018 had a slight increase when compared with 2012, though not significantly $(0.358$ vs $0.333 ; p>0.05$, Fig. 2 f, Fig. 5 c). There was also only tiny fluctuation between MIR of 2012 and 2018 within each specific HDI group (Fig. 2f).

\subsubsection{Kidney cancer}

The incidence of kidney cancer also reduced during 2012-2018 (337 860 vs 403 262). In the scatter diagram of HDI-MIR, current MIR of kidney cancer also shifted in the direction when comparing with 2012 (Fig. 5d). Remarkably, two regression lines were nearly parallel $\left(r_{2018}=-1.153, r_{2012}=-1.231 ; p<0.01\right)$. Meanwhile, MIRs of kidney cancer declined overall, across all development status $(p<0.01$ for the low-, $p$ $<0.0001$ for the medium-, $p<0.001$ for the high-, and $p=0.23$ for the very-high-HDI group; Fig. 2i).

\section{Discussion}


Our study aims to clarify the latest epidemiology of urologic cancer and the contribution of national development to urologic cancer outcomes. Mortality-to-incidence ratio (MIR) and 5-year net survival both represent cancer outcomes. MIR is regarded as a quite useful surrogate indicator of oncology care effectiveness, which could be a comprehensive result of screening, diagnostic modality, treatment and follow-up [12,18]. Meanwhile, 5-year net survival might be labeled with more importance, since cancer patients who survive for a considerable time span can, in a way, be considered cured $[17,19]$. In the current study, we proved that all three urologic cancers MIR negatively, while incidence and survival rates positively correlated with HDI.

\subsection{Prostate cancer}

Incidence of prostate cancer was highest in countries with very-high HDI. The public recommendation and prevalence of early diagnostics for prostate cancer in more developed countries, by PSA testing and detection of latent cancer in transurethral prostatectomy or puncture biopsy, led to higher incidence rates. For example, the commercial availability of PSA testing from 1980s brought about the intensively use of the test and rapid growth in new cases, first in the United States and within a few years, in Europe, Australia/New Zealand, and Canada $[1,20,21]$. Another explanation could be attributed to age. Nearly $75 \%$ of new prostate cancer cases occurring in people aged over 85 years, and incidence of prostate cancer is directly correlated with age [22,15]. Since life expectancy is one of key elements of HDI, there is no doubt that countries with higher HDI had a greater prostate cancer incidence. Moreover, ethnic and genetic predisposition could also be blamed for prostate cancer morbidity. The rates are highest among men of African descent in the United States and the Caribbean [23]. That's why Barbados and Bahama topped in the incidence rates of prostate cancer with a relatively lower HDI within high-HDI group.

The correlation between cancer outcomes and HDI seemed to be driven by national inequalities in health care, resulting in deviations in treatment effectiveness. First of all, the widespread access to diagnostic services and screening tests in more developed countries leads to increased diagnosis at earlier stages of disease and better clinical outcomes. However, we could not deny the overdiagnosis associated with PSA screening. Some new biomarkers sparing those who overdiagnosed are under development (e.g., PCA3 or TMPRSS-ERG fusions) [24]. Secondly, the delivery of urologic oncology care is susceptible to regional variation. Access to effective radiation equipment and neoadjuvant hormonal therapy is linked to a country's wealth. Advances in immunotherapy and robotic surgery, though promising, are not feasible or affordable for generalized application in settings with limited health care resources [25-27].

Multiple studies have reported that the detected cases of prostate cancer from 1990 to 2010 were increasing rapidly [2,28]. However, incidence of prostate cancer was on its downhill from 2012 to 2018. The 2012 recommendation against the routine use of PSA testing by the US Preventive Services Task Force (USPSTF) may have partly driven trends downward [29]. American Urological Association (AUA) stated in 2013 update that routine screening of men aged 40-54 years and men with less than a 10- to 15year life expectancy was not recommended [30]. Meanwhile, our analysis revealed that from 2012 to 2018 , the integral worldwide HDI values increased, along with the decline in MIRs and improvement in 
survival of prostate cancer. Scientific advances have resulted in rapidly growing medical technology and treatment strategies. The development of laparoscopic and robotic surgery, especially the da Vinci Surgical System (Intuitive Surgical, Sunnyvale, CA), has offered a less invasive approach while ensuring oncological remission and expected survival [25]. Meanwhile, novel approaches like immune checkpoint blockades have also emerged as powerful methods against tumor [26,27].

\subsection{Bladder Cancer}

Higher incidence rates of bladder cancer could be observed in more developed countries, especially in Southern and Western Europe. Chemical or environmental exposures are major risk factors for bladder cancer, including smoking, obesity, alcohol drinking and red-meat consumption [31,32]. These risk factors have been reported by the World Health Organization as alarmingly high across Europe [33]. Among above, cigarette smoking is the most important environmental factor [31]. Smokers have a two- to fivefold increased risk of bladder cancer relative to never-smokers [34]. At present, smoking prevalence is highest among both genders in Europe [35]. More exposures to carcinogenic agents like aromatic amines in dye industry in Europe also leads to higher morbidity [36]. Other likely reason is widespread practice of initial assessment in more developed regions, consisting of voided urine cytology, cystoscopy, radiological investigation of the upper tracts for haematuria and other non-specific urinary symptoms [34,32]. MIR of bladder cancer appeared to be high in less developed regions. Higher-quality medical care and better health awareness were possessed in highly developed areas, as stated in Prostate Cancer.

The evolving burden of bladder cancers since 1990 could be attributed to following forces: population growth and aging, the improvement in diagnostic technology, and the changing risks of exposures like tobacco use and obesity [2]. While from 2012 to 2018, patients went in declines in both incidence and MIR of bladder cancer worldwide. Primary prevention of tobacco use is the most effective strategy for bladder cancer prophylaxis [22]. Currently, under the policies of tobacco control [37], smoking cessation is becoming common and may explain how the bladder cancer burden is becoming retrieving, especially in more highly educated and health-focused populations [32,22]. Meanwhile, decreasing incidence and earlier diagnosis also leads to stage migration to earlier stage disease. Another driver for cancer outcomes improvement could be due to improved endoscopic system for cystoscopic surveillance [38]; more transurethral bladder resection for non-invasive cancer [31]; radical cystoprostatectomy and anterior exenteration by robotic surgery with less invasive injury to patients [39]; better intravesical therapy, such as the Bacillus Calmette-Guerin (BCG) and updated chemotherapy [31]. Moreover, EGFR, ERBB2 and VEGF are validated targets for cancer therapy but still remain the subject of intense investigation so far $[40,27]$.

\subsection{Kidney cancer}

The incidence of kidney cancer correlated positively with country-specific HDI. Risk factors such as obesity, hypertension and diabetes might be attributed to the morbidity of kidney cancer [41-44]. Currently, the prevalence of both conventional and ambulatory hypertension correlated inversely with national HDI [45]. The global burden of obesity and diabetes was also predominantly driven by high-income countries as well [46]. As with bladder cancer, smoking is one of the most essential reasons for kidney cancer [47]. 
Furthermore, the frequency and quality of cross-sectional imaging tend to be higher in developed nations [22]. Similarly, MIR of kidney cancer negatively correlated with certain national HDI. The stage of kidney cancer at first diagnosis crucially determines its prognosis and differs markedly across countries. Smaller masses tend to be identified easier at presentation in developed countries for non-specific symptoms [47]. Same as immunotherapy, targeted therapy and advanced surgery procedures.

The global burden and MIR of kidney cancer stagnated or decreased in the majority of countries examined from 2012 to 2018 . As discussed, more developed preventative efforts and treating methods could lead to a decrease in cancer incidence and mortality.

There are some limitations to our study. First, cancer registration in relatively less-developed nations could suffer from higher chance of under-reporting due to limited communication infrastructure and less robust recording system; low income and lower willingness to utilize healthcare services; relative lack of clinical services and investigation tests. GLOBOCAN and CONCORD-3 often extrapolates data for certain developing nations based on data from subnational areas or major cities. Second, discrepancies between the reliability of incidence and mortality reporting limit MIR interpretation, as mortality data are generally more accurate than incidence. Although we exclude extreme values, there is no way to correct this bias in our analysis. Third, we could not establish cause-and-effect relationships in correlational analysis.

\section{Conclusions}

In conclusion, HDI values are significantly correlated with urologic cancer incidence, MIRs and survival rates. More developed countries are more likely to have higher incidence and mortality rates, but lower MIRs. From 2012 to 2018, new cases of urologic cancer have declined, with apparent improvement in clinical outcomes. Disparities in cancer health care should compel us to exert greater effort in improving awareness, universal health coverage, access to either publicly funded or affordable screening programs and treatment in low HDI countries.

\section{Declarations}

\section{Author's Contribution}

Shi-Geng Zhang: Project development

Nan Zhang: Project development, Data analysis, Manuscript writing

Hua Mu: Data analysis, Manuscript writing

Yan-rou Jiang: Data collection

\section{Conflict of interest}


The authors declare no conflicts of interest.

\section{Ethical approval}

This article does not contain any studies with human participants or animals performed by any of the authors.

\section{Acknowledgement}

This work was financially supported by the Zhejiang Provincial Natural Science Foundation (grant numbers Y18H050009), Zhejiang Provincial Science and Technology Department Public Welfare Projects (grant number LGF19H050006) and General research program of Zhejiang Provincial Department of health (grant number 2018265438).

\section{References}

1. Bray F, Ferlay J, Soerjomataram I, Siegel RL, Torre LA, Jemal A (2018) Global cancer statistics 2018: GLOBOCAN estimates of incidence and mortality worldwide for 36 cancers in 185 countries. CA: a cancer journal for clinicians 68 (6):394-424. doi:10.3322/caac.21492

2. Dy GW, Gore JL, Forouzanfar MH, Naghavi M, Fitzmaurice C (2017) Global Burden of Urologic Cancers, 1990-2013. European urology 71 (3):437-446. doi:10.1016/j.eururo.2016.10.008

3. Loughlin KR (2010) The future of urologic cancer care in the United States: our finest hour or a bridge too far. Urologic oncology 28 (6):581-584. doi:10.1016/j.urolonc.2010.08.016

4. Pang C, Guan Y, Li H, Chen W, Zhu G (2016) Urologic cancer in China. Japanese journal of clinical oncology 46 (6):497-501. doi:10.1093/jjco/hyw034

5. Umbas R, Safriadi F, Mochtar CA, Djatisoesanto W, Hamid AR (2015) Urologic cancer in Indonesia. Japanese journal of clinical oncology 45 (8):708-712. doi:10.1093/jjco/hyv066

6. Akaza H (2016) Urologic cancer in Japan: role of Japan at the frontier of issues in Asia. Japanese journal of clinical oncology 46 (1):23-30. doi:10.1093/jjco/hyv123

7. Hung CF, Yang CK, Ou YC (2016) Urologic cancer in Taiwan. Japanese journal of clinical oncology 46 (7):605-609. doi:10.1093/jjco/hyw038

8. Lojanapiwat B (2015) Urologic cancer in Thailand. Japanese journal of clinical oncology 45 (11):1007-1015. doi:10.1093/jjco/hyv125

9. Koo KC, Lee KS, Chung BH (2015) Urologic cancers in Korea. Japanese journal of clinical oncology 45 (9):805-811. doi:10.1093/jjco/hyv096

10. Hancock T (1993) Health, human development and the community ecosystem: three ecological models. Health Promotion International 8 (1):41-47. doi:10.1093/heapro/8.1.41 
11. United Nations Development Programme. Human Development Indices and Indicators, 2018 Statistical Update. (2018). http://hdr.undp.org/en/2018-update.

12. Hu QD, Zhang Q, Chen W, Bai XL, Liang TB (2013) Human development index is associated with mortality-to-incidence ratios of gastrointestinal cancers. World journal of gastroenterology 19 (32):5261-5270. doi:10.3748/wjg.v19.i32.5261

13. Fidler MM, Bray F (2018) Global Cancer Inequalities. Front Oncol 8:293. doi:10.3389/fonc. 2018.00293

14. Hassanipour-Azgomi S, Mohammadian-Hafshejani A, Ghoncheh M, Towhidi F, Jamehshorani S, Salehiniya $\mathrm{H}$ (2016) Incidence and mortality of prostate cancer and their relationship with the Human Development Index worldwide. Prostate international 4 (3):118-124. doi:10.1016/j.prnil.2016.07.001

15. Pakzad R, Mohammadian-Hafshejani A, Ghoncheh M, Pakzad I, Salehiniya H (2015) The incidence and mortality of prostate cancer and its relationship with development in Asia. Prostate international 3 (4):135-140. doi:10.1016/j.prnil.2015.09.001

16. Schneiderman MA (1968) Cancer Incidence in Five Continents: A Technical Report. Richard Doll, Peter Payne, and John Waterhouse (eds) New York: Springer-Verlag, 1966244 pp \$950 28 (4):804804

17. Allemani C, Matsuda T, Di Carlo V, Harewood R, Matz M, Niksic M, Bonaventure A, Valkov M, Johnson CJ, Esteve J, Ogunbiyi OJ, Azevedo ESG, Chen WQ, Eser S, Engholm G, Stiller CA, Monnereau A, Woods RR, Visser O, Lim GH, Aitken J, Weir HK, Coleman MP, Group CW (2018) Global surveillance of trends in cancer survival 2000-14 (CONCORD-3): analysis of individual records for 37513025 patients diagnosed with one of 18 cancers from 322 population-based registries in 71 countries. Lancet 391 (10125):1023-1075. doi:10.1016/S0140-6736(17)33326-3

18. Hebert JR, Daguise VG, Hurley DM, Wilkerson RC, Mosley CM, Adams SA, Puett R, Burch JB, Steck SE, Bolick-Aldrich SW (2009) Mapping cancer mortality-to-incidence ratios to illustrate racial and sex disparities in a high-risk population. Cancer 115 (11):2539-2552. doi:10.1002/cncr.24270

19. Berkson J, Gage RP (1952) Survival Curve for Cancer Patients Following Treatment. Journal of the American Statistical Association 47 (259):501-515. doi:10.1080/01621459.1952.10501187

20. Kvale R, Auvinen A, Adami HO, Klint A, Hernes E, Moller B, Pukkala E, Storm HH, Tryggvadottir L, Tretli S, Wahlqvist R, Weiderpass E, Bray F (2007) Interpreting trends in prostate cancer incidence and mortality in the five Nordic countries. Journal of the National Cancer Institute 99 (24):1881-1887. doi:10.1093/jnci/djm249

21. Zhou CK, Check DP, Lortet-Tieulent J, Laversanne M, Jemal A, Ferlay J, Bray F, Cook MB, Devesa SS (2016) Prostate cancer incidence in 43 populations worldwide: An analysis of time trends overall and by age group. International journal of cancer 138 (6):1388-1400. doi:10.1002/ijc.29894

22. Greiman AK, Rosoff JS, Prasad SM (2017) Association of Human Development Index with global bladder, kidney, prostate and testis cancer incidence and mortality. BJU international 120 (6):799807. doi:10.1111/bju.13875 
23. Rebbeck TR, Devesa SS, Chang BL, Bunker CH, Cheng I, Cooney K, Eeles R, Fernandez P, Giri VN, Gueye SM, Haiman CA, Henderson BE, Heyns CF, Hu JJ, Ingles SA, Isaacs W, Jalloh M, John EM, Kibel AS, Kidd LR, Layne P, Leach RJ, Neslund-Dudas C, Okobia MN, Ostrander EA, Park JY, Patrick AL, Phelan CM, Ragin C, Roberts RA, Rybicki BA, Stanford JL, Strom S, Thompson IM, Witte J, Xu J, Yeboah E, Hsing AW, Zeigler-Johnson CM (2013) Global patterns of prostate cancer incidence, aggressiveness, and mortality in men of african descent. Prostate cancer 2013:560857. doi:10.1155/2013/560857

24. Cuzick J, Thorat MA, Andriole G, Brawley OW, Brown PH, Culig Z, Eeles RA, Ford LG, Hamdy FC, Holmberg L, Ilic D, Key TJ, La Vecchia C, Lilja H, Marberger M, Meyskens FL, Minasian LM, Parker C, Parnes HL, Perner S, Rittenhouse H, Schalken J, Schmid HP, Schmitz-Drager BJ, Schroder FH, Stenzl A, Tombal B, Wilt TJ, Wolk A (2014) Prevention and early detection of prostate cancer. The Lancet Oncology 15 (11):e484-492. doi:10.1016/s1470-2045(14)70211-6

25. Forsmark A, Gehrman J, Angenete E, Bjartell A, Bjorholt I, Carlsson S, Hugosson J, Marlow T, Stinesen-Kollberg K, Stranne J, Wallerstedt A, Wiklund P, Wilderang U, Haglind E (2018) Health Economic Analysis of Open and Robot-assisted Laparoscopic Surgery for Prostate Cancer Within the Prospective Multicentre LAPPRO Trial. European urology 74 (6):816-824. doi:10.1016/j.eururo.2018.07.038

26. Abida W, Cheng ML, Armenia J, Middha S, Autio KA, Vargas HA, Rathkopf D, Morris MJ, Danila DC, Slovin SF, Carbone E, Barnett ES, Hullings M, Hechtman JF, Zehir A, Shia J, Jonsson P, Stadler ZK, Srinivasan P, Laudone VP, Reuter V, Wolchok JD, Socci ND, Taylor BS, Berger MF, Kantoff PW, Sawyers CL, Schultz N, Solit DB, Gopalan A, Scher HI (2018) Analysis of the Prevalence of Microsatellite Instability in Prostate Cancer and Response to Immune Checkpoint Blockade. JAMA oncology. doi:10.1001/jamaoncol.2018.5801

27. Zhao SG, Lehrer J, Chang SL, Das R, Erho N, Liu Y, Sjostrom M, Den RB, Freedland SJ, Klein EA, Karnes RJ, Schaeffer EM, Xu M, Speers C, Nguyen PL, Ross AE, Chan JM, Cooperberg MR, Carroll PR, Davicioni E, Fong L, Spratt DE, Feng FY (2018) The Immune Landscape of Prostate Cancer and Nomination of PD-L2 as a Potential Therapeutic Target. Journal of the National Cancer Institute. doi:10.1093/jnci/djy141

28. Bosetti C, Bertuccio P, Chatenoud L, Negri E, La Vecchia C, Levi F (2011) Trends in mortality from urologic cancers in Europe, 1970-2008. European urology 60 (1):1-15. doi:10.1016/j.eururo.2011.03.047

29. Grossman DC, Curry SJ, Owens DK, Bibbins-Domingo K, Caughey AB, Davidson KW, Doubeni CA, Ebell M, Epling JW, Jr., Kemper AR, Krist AH, Kubik M, Landefeld CS, Mangione CM, Silverstein M, Simon MA, Siu AL, Tseng CW (2018) Screening for Prostate Cancer: US Preventive Services Task Force Recommendation Statement. Jama 319 (18):1901-1913. doi:10.1001/jama.2018.3710

30. Carter HB, Albertsen PC, Barry MJ, Etzioni R, Freedland SJ, Greene KL, Holmberg L, Kantoff P, Konety BR, Murad MH, Penson DF, Zietman AL (2013) Early detection of prostate cancer: AUA Guideline. The Journal of urology 190 (2):419-426. doi:10.1016/j.juro.2013.04.119 
31. Kaufman DS, Shipley WU, Feldman AS (2009) Bladder cancer. Lancet 374 (9685):239-249. doi:10.1016/s0140-6736(09)60491-8

32. Wong MCS, Fung FDH, Leung C, Cheung WWL, Goggins WB, Ng CF (2018) The global epidemiology of bladder cancer: a joinpoint regression analysis of its incidence and mortality trends and projection. Scientific reports 8 (1):1129. doi:10.1038/s41598-018-19199-z

33. Schmitz-Drager BJ, Droller M, Lokeshwar VB, Lotan Y, Hudson MA, van Rhijn BW, Marberger MJ, Fradet Y, Hemstreet GP, Malmstrom PU, Ogawa O, Karakiewicz PI, Shariat SF (2015) Molecular markers for bladder cancer screening, early diagnosis, and surveillance: the WHO/ICUD consensus. Urologia internationalis 94 (1):1-24. doi:10.1159/000369357

34. Silverman D MA, Devasa S. (1996) Bladder cancer. In: Schottenfeld D FJJ (ed) Cancer Epidemiology and Prevention. 2 edn. Oxford University Press, New York, pp 1156-1179

35. Bilano V, Gilmour S, Moffiet T, d'Espaignet ET, Stevens GA, Commar A, Tuyl F, Hudson I, Shibuya K (2015) Global trends and projections for tobacco use, 1990-2025: an analysis of smoking indicators from the WHO Comprehensive Information Systems for Tobacco Control. Lancet 385 (9972):966976. doi:10.1016/s0140-6736(15)60264-1

36. Kauppinen T, Toikkanen J, Pedersen D, Young R, Ahrens W, Boffetta P, Hansen J, Kromhout H, Maqueda Blasco J, Mirabelli D, de la Orden-Rivera V, Pannett B, Plato N, Savela A, Vincent R, Kogevinas M (2000) Occupational exposure to carcinogens in the European Union. Occupational and environmental medicine 57 (1):10-18

37. Organization. WH WHO Framework Convention on Tobacco Control. Accessed 06/07/2017

38. Zlatev DV, Altobelli E, Liao JC (2015) Advances in imaging technologies in the evaluation of highgrade bladder cancer. The Urologic clinics of North America 42 (2):147-157, vii. doi:10.1016/j.ucl.2015.01.001

39. Parekh DJ, Reis IM, Castle EP, Gonzalgo ML, Woods ME, Svatek RS, Weizer AZ, Konety BR, Tollefson M, Krupski TL, Smith ND, Shabsigh A, Barocas DA, Quek ML, Dash A, Kibel AS, Shemanski L, Pruthi RS, Montgomery JS, Weight CJ, Sharp DS, Chang SS, Cookson MS, Gupta GN, Gorbonos A, Uchio EM, Skinner E, Venkatramani V, Soodana-Prakash N, Kendrick K, Smith JA, Jr., Thompson IM (2018) Robot-assisted radical cystectomy versus open radical cystectomy in patients with bladder cancer (RAZOR): an open-label, randomised, phase 3, non-inferiority trial. Lancet 391 (10139):2525-2536. doi:10.1016/s0140-6736(18)30996-6

40. Daizumoto K, Yoshimaru T, Matsushita Y, Fukawa T, Uehara H, Ono M, Komatsu M, Kanayama HO, Katagiri T (2018) A DDX31/Mutant-p53/EGFR Axis Promotes Multistep Progression of MuscleInvasive Bladder Cancer. Cancer research 78 (9):2233-2247. doi:10.1158/0008-5472.can-17-2528

41. Chow WH, Gridley G, Fraumeni JF, Jr., Jarvholm B (2000) Obesity, hypertension, and the risk of kidney cancer in men. The New England journal of medicine 343 (18):1305-1311.

doi:10.1056/nejm200011023431804

42. Zucchetto A, Dal Maso L, Tavani A, Montella M, Ramazzotti V, Talamini R, Canzonieri V, Garbeglio A, Negri E, Franceschi S, La Vecchia C (2007) History of treated hypertension and diabetes mellitus and 
risk of renal cell cancer. Annals of oncology : official journal of the European Society for Medical Oncology 18 (3):596-600. doi:10.1093/annonc/mdl438

43. Sanfilippo KM, McTigue KM, Fidler CJ, Neaton JD, Chang Y, Fried LF, Liu S, Kuller LH (2014) Hypertension and obesity and the risk of kidney cancer in 2 large cohorts of US men and women. Hypertension (Dallas, Tex : 1979) 63 (5):934-941. doi:10.1161/hypertensionaha.113.02953

44. Graff RE, Sanchez A, Tobias DK, Rodriguez D, Barrisford GW, Blute ML, Li Y, Sun Q, Preston MA, Wilson KM, Cho E (2018) Type 2 Diabetes in Relation to the Risk of Renal Cell Carcinoma Among Men and Women in Two Large Prospective Cohort Studies. Diabetes care 41 (7):1432-1437. doi:10.2337/dc17-2518

45. Melgarejo JD, Maestre GE, Thijs L, Asayama K, Boggia J, Casiglia E, Hansen TW, Imai Y, Jacobs L, Jeppesen J, Kawecka-Jaszcz K, Kuznetsova T, Li Y, Malyutina S, Nikitin Y, Ohkubo T, Stolarz-Skrzypek K, Wang JG, Staessen JA (2017) Prevalence, Treatment, and Control Rates of Conventional and Ambulatory Hypertension Across 10 Populations in 3 Continents. Hypertension (Dallas, Tex : 1979) 70 (1):50-58. doi:10.1161/hypertensionaha.117.09188

46. King H, Aubert RE, Herman WH (1998) Global burden of diabetes, 1995-2025: prevalence, numerical estimates, and projections. Diabetes care 21 (9):1414-1431

47. Znaor A, Lortet-Tieulent J, Laversanne M, Jemal A, Bray F (2015) International variations and trends in renal cell carcinoma incidence and mortality. European urology 67 (3):519-530. doi:10.1016/j.eururo.2014.10.002

\section{Tables}

Table 1. National HDI and 5-year net survival values of prostate cancer from 2012 to 2018 


\begin{tabular}{|c|c|c|c|c|c|c|}
\hline \multirow[b]{2}{*}{ Country } & \multicolumn{2}{|r|}{2012} & \multicolumn{2}{|r|}{2018} & \multicolumn{2}{|c|}{ Transitions in a d } \\
\hline & HDI & Survival & HDI & Survival & $\Delta_{\text {HDI }}$ & $\Delta_{\text {survival }}$ \\
\hline Algeria & 0.713 & 50.3 & 0.754 & 64.1 & 0.041 & 13.8 \\
\hline Argentina & 0.811 & 83.6 & 0.825 & 87.6 & 0.014 & 4 \\
\hline Australia & 0.938 & 93.2 & 0.939 & 94.5 & 0.001 & 1.3 \\
\hline Austria & 0.895 & 90.8 & 0.908 & 90.2 & 0.013 & -0.6 \\
\hline Belgium & 0.897 & 93.2 & 0.916 & 93.8 & 0.019 & 0.6 \\
\hline Brazil & 0.73 & 92.5 & 0.759 & 91.6 & 0.029 & -0.9 \\
\hline Bulgaria & 0.782 & 54.8 & 0.813 & 68.3 & 0.031 & 13.5 \\
\hline Canada & 0.911 & 94.2 & 0.926 & 93.6 & 0.015 & -0.6 \\
\hline Chile & 0.819 & 84.4 & 0.843 & 82 & 0.024 & -2.4 \\
\hline China & 0.699 & 62.5 & 0.752 & 69.2 & 0.053 & 6.7 \\
\hline Colombia & 0.719 & 87.8 & 0.747 & 80.3 & 0.028 & -7.5 \\
\hline Costa Rica & 0.773 & 92.6 & 0.794 & 93.2 & 0.021 & 0.6 \\
\hline Croatia & 0.805 & 78.3 & 0.831 & 80.9 & 0.026 & 2.6 \\
\hline Cuba & 0.78 & 53.8 & 0.777 & 71.4 & -0.003 & 17.6 \\
\hline Cyprus & 0.848 & 98.3 & 0.869 & 99.2 & 0.021 & 0.9 \\
\hline Czech Republic & 0.873 & 81.5 & 0.888 & 85.3 & 0.015 & 3.8 \\
\hline Denmark & 0.901 & 82.5 & 0.929 & 85.6 & 0.028 & 3.1 \\
\hline Ecuador & 0.724 & 80.7 & 0.752 & 82.2 & 0.028 & 1.5 \\
\hline Estonia & 0.846 & 83.2 & 0.871 & 86.3 & 0.025 & 3.1 \\
\hline Finland & 0.892 & 93.4 & 0.920 & 93.2 & 0.028 & -0.2 \\
\hline France & 0.893 & 93.6 & 0.901 & 93.1 & 0.008 & -0.5 \\
\hline Germany & 0.92 & 91.8 & 0.936 & 91.6 & 0.016 & -0.2 \\
\hline Iceland & 0.906 & 89.7 & 0.935 & 90.8 & 0.029 & 1.1 \\
\hline India & 0.554 & 33.2 & 0.640 & 44.3 & 0.086 & 11.1 \\
\hline Ireland & 0.916 & 89.7 & 0.938 & 91.1 & 0.022 & 1.4 \\
\hline Israel & 0.9 & 95.7 & 0.903 & 95.6 & 0.003 & -0.1 \\
\hline Italy & 0.881 & 89.6 & 0.880 & 89.5 & -0.001 & -0.1 \\
\hline Japan & 0.912 & 91.4 & 0.909 & 93 & -0.003 & 1.6 \\
\hline Jordan & 0.7 & 88.6 & 0.735 & 86.1 & 0.035 & -2.5 \\
\hline Korea, Republic of & 0.909 & 87.3 & 0.903 & 89.9 & -0.006 & 2.6 \\
\hline Kuwait & 0.79 & 71.9 & 0.803 & 84 & 0.013 & 12.1 \\
\hline Latvia & 0.814 & 88.8 & 0.847 & 90.4 & 0.033 & 1.6 \\
\hline Lithuania & 0.818 & 93.8 & 0.858 & 94.3 & 0.040 & 0.5 \\
\hline Malaysia & 0.769 & 74.9 & 0.802 & 87.7 & 0.033 & 12.8 \\
\hline Malta & 0.847 & 86.4 & 0.878 & 88.2 & 0.031 & 1.8 \\
\hline Mauritius & 0.737 & 61.8 & 0.790 & 63.5 & 0.053 & 1.7 \\
\hline Netherlands & 0.921 & 87.5 & 0.931 & 88.5 & 0.010 & 1 \\
\hline New Zealand & 0.919 & 89.3 & 0.917 & 90.3 & -0.002 & 1 \\
\hline Nigeria & 0.471 & 73.9 & 0.532 & 58.7 & 0.061 & -15.2 \\
\hline Norway & 0.955 & 90.3 & 0.953 & 92.9 & -0.002 & 2.6 \\
\hline Poland & 0.821 & 75 & 0.865 & 78.1 & 0.044 & 3.1 \\
\hline Portugal & 0.816 & 90 & 0.847 & 90.9 & 0.031 & 0.9 \\
\hline Qatar & 0.834 & 98.2 & 0.856 & 89.6 & 0.022 & -8.6 \\
\hline
\end{tabular}




\begin{tabular}{cccccccc} 
Romania & 0.786 & 78.2 & 0.811 & 77.1 & 0.025 & -1.1 \\
\hline Russian Federation & 0.788 & 68.6 & 0.816 & 79.3 & 0.028 & 10.7 \\
\hline Singapore & 0.895 & 86.7 & 0.932 & 87.8 & 0.037 & 1.1 \\
\hline Slovakia & 0.84 & 74.4 & 0.855 & 74.7 & 0.015 & 0.3 \\
\hline Slovenia & 0.892 & 83.2 & 0.896 & 85 & 0.004 & 1.8 \\
\hline South Africa & 0.629 & 38.6 & 0.699 & 37.8 & 0.070 & -0.8 \\
\hline Spain & 0.885 & 90.4 & 0.891 & 89.7 & 0.006 & -0.7 \\
\hline Sweden & 0.916 & 90.1 & 0.933 & 90.7 & 0.017 & 0.6 \\
\hline Switzerland & 0.913 & 88.6 & 0.944 & 89.2 & 0.031 & 0.6 \\
\hline Thailand & 0.69 & 71.8 & 0.755 & 68 & 0.065 & -3.8 \\
\hline Turkey & 0.722 & 81.2 & 0.791 & 83.8 & 0.069 & 2.6 \\
\hline United Kingdom & 0.875 & 86.7 & 0.922 & 88.7 & 0.047 & 2 \\
\hline United States of America & 0.937 & 98.1 & 0.924 & 97.4 & -0.013 & -0.7 \\
\hline Uruguay & 0.792 & 84.7 & 0.804 & 86.5 & 0.012 & 1.8 \\
\hline
\end{tabular}

Note: A total of 57 countries with survival rates available in both years; HDI, Human Development Index.

\section{Figures}
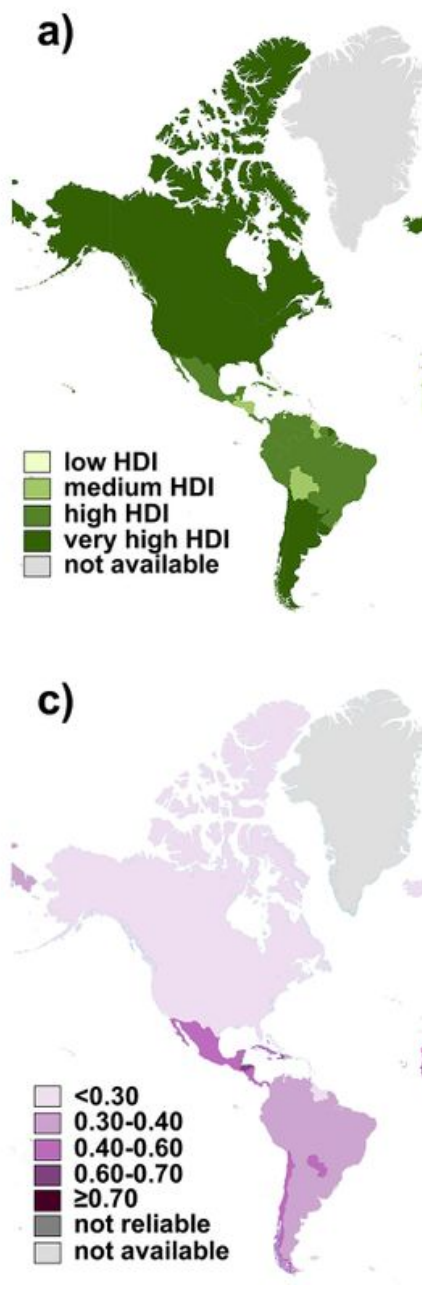

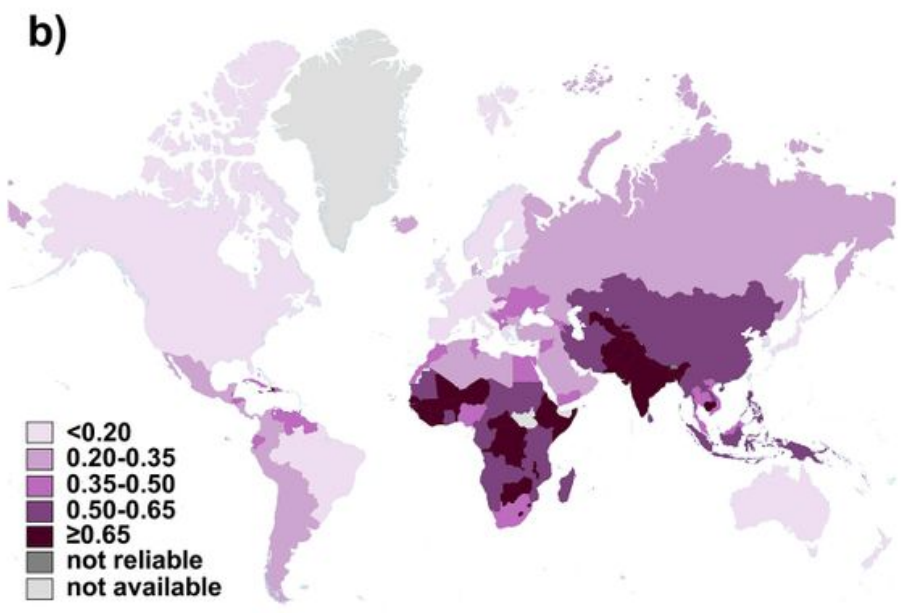

d)
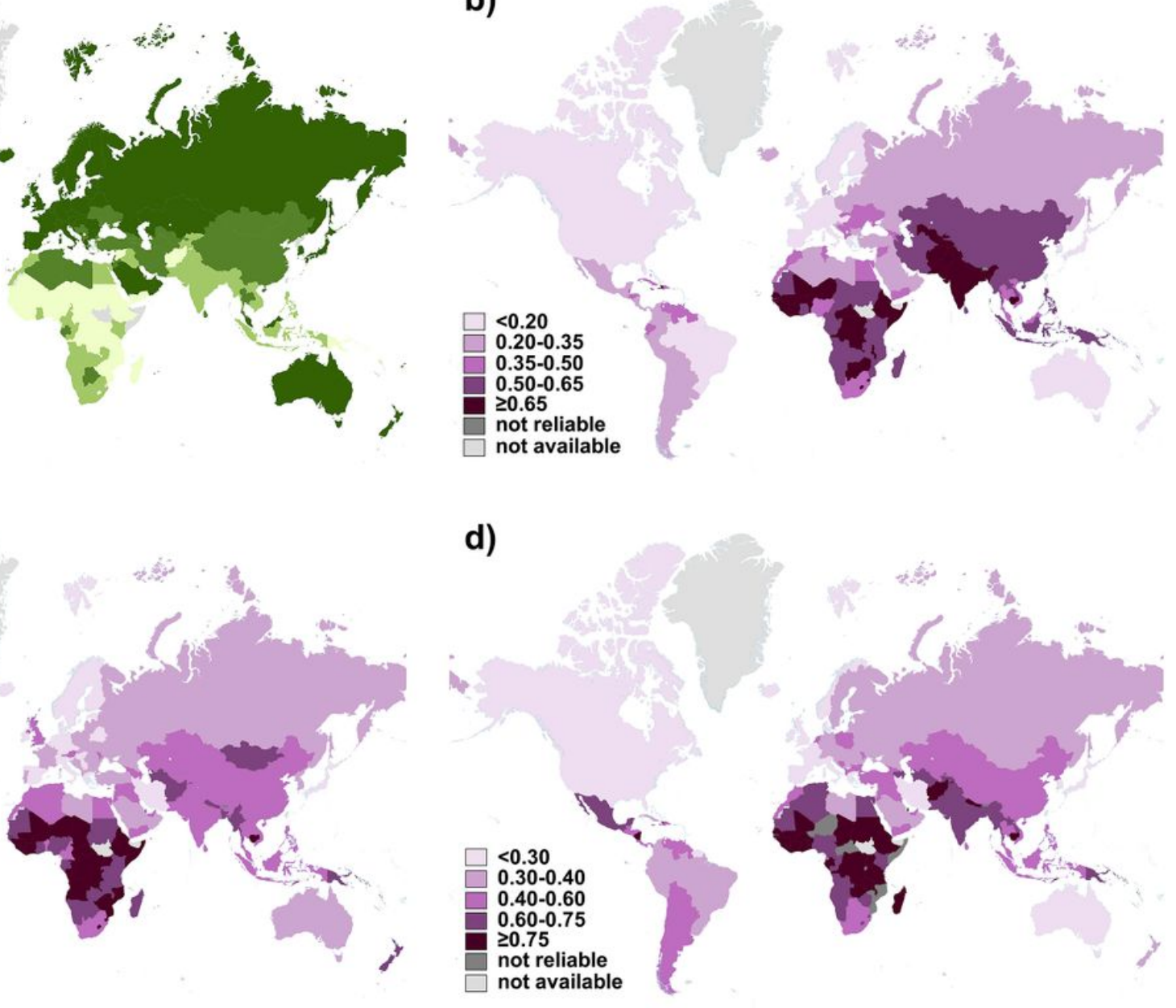
Worldwide distribution of HDI values and MIR of urologic cancer. A total of 174 countries were included into analysis. (a) Countries were classified into 4 tiers according to different levels of HDI (green). (b) calculated MIR results of prostate cancer, (c) bladder cancer, and (d) kidney cancer were indicated in a purple-gradient color scale. Countries with data unavailable (light gray) or unreliable (dark gray) were denoted. HDI, Human Development Index; MIR, mortality-to-incidence ratio.
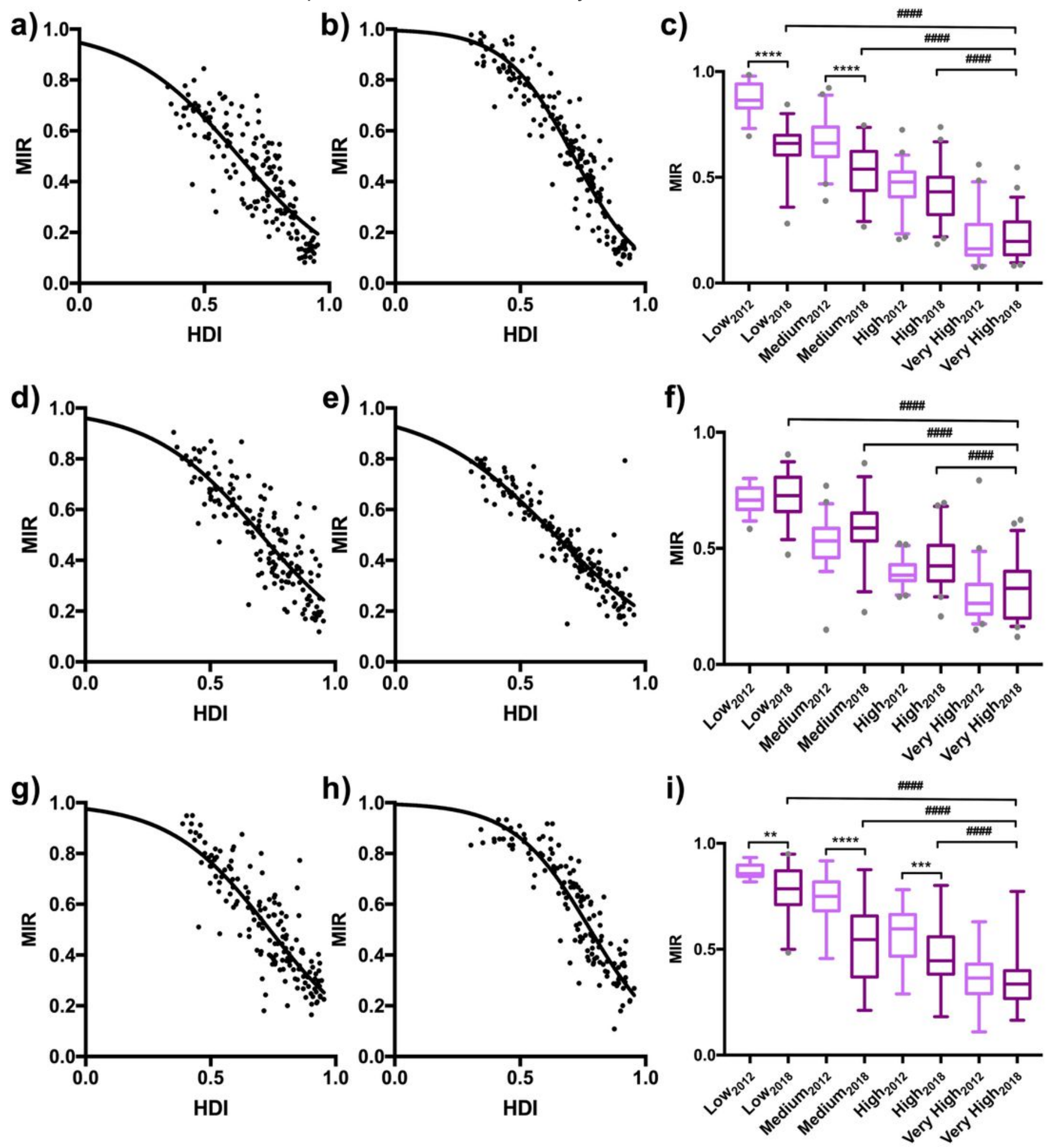
Figure 2

Correlation between HDI and MIR and its transition from 2012 to 2018. The patterns of urologic cancer MIRs to national HDIs with the best-fit lines by modified nonlinear regression ("dose-to-response" model) were presented as following: (a) prostate cancer in 2018 (slope $=-1.962, \mathrm{HDI} 50=0.639, \mathrm{R} 2=0.687$ ) and (b) in 2012 (slope = -3.177, HDI50 = 0.713, R2 = 0.891); (d) bladder cancer in 2018 (slope = -1.967, HDI50 $=0.704, \mathrm{R} 2=0.733$ ) and (e) in 2012 (slope $=-1.720, \mathrm{HDI} 50=0.640, \mathrm{R} 2=0.835)$; (g) kidney cancer in 2018 (slope $=-2.178, \mathrm{HDI50}=0.736, \mathrm{R} 2=0.737)$ and $(\mathrm{h})$ in 2012 (slope $=-2.835, \mathrm{HDI} 50=0.780, \mathrm{R} 2=$ 0.824 ). MIRs of (c) prostate, (f) bladder and (i) kidney cancer in the $4 \mathrm{HDI}$ groups, with significant differences among the very high, high, medium and low groups and a decreasing tendency in certain groups between 2012 (light purple) and 2018 (dark purple). \#\#\#\# p 0.0001, vs. very-high-HDI countries in 2018, one-way ANOVA followed by Tukey-Kramer post hoc test. The statistical significance among countries in 2012 was not indicated. ${ }^{\star *} p<0.01$, ${ }^{\star \star *} p<0.001$, ${ }^{\star \star \star *} p<0.0001,2008$ vs. 2018 in specific corresponding group, unpaired t-test.
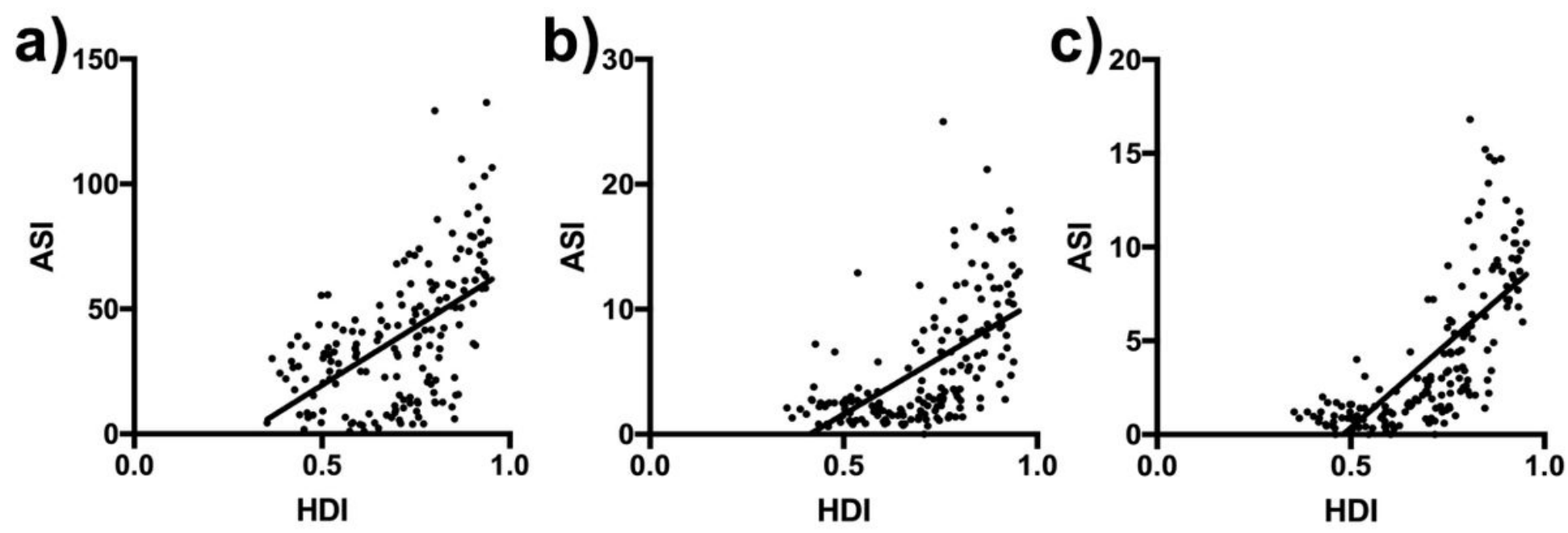

Figure 3

The association between incidence rates of urologic cancers and HDI. (a) The national age-standard incidence rates of prostate cancer correlated positively $(r=0.556, p<0.0001)$ with HDIs via linear regression (slope $=93.54)$ in 2018. Similar results for $(b)$ bladder cancer $(r=0.661, p<0.0001$, slope $=$ $18.22)$ and $(c)$ kidney cancer $(r=0.816, p<0.0001$, slope $=18.06)$. 
a)
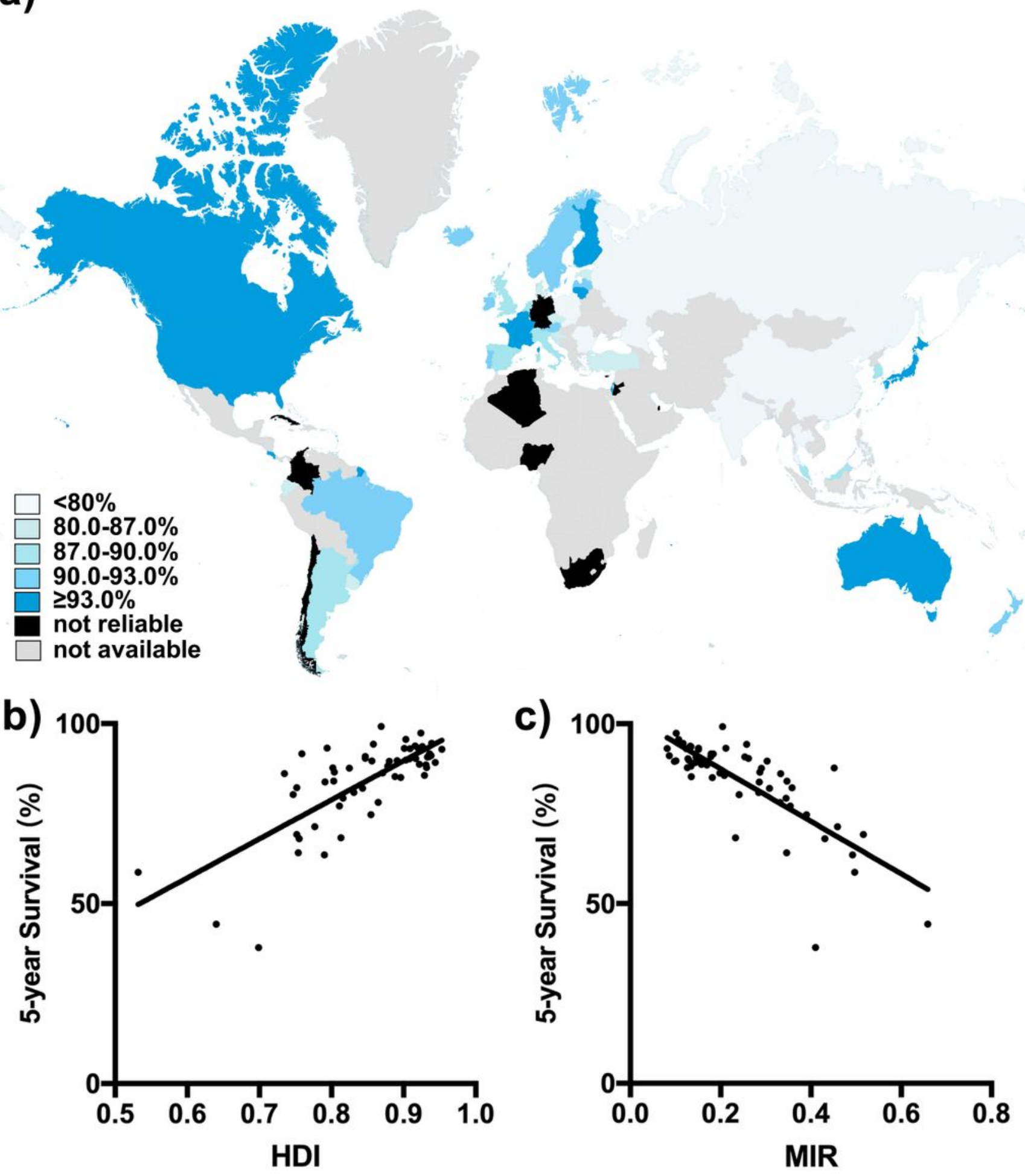

Figure 4

Distributions of prostate cancer survival and its correlation with HDI values and MIRs. (a) Distribution of regional estimated 5-year net survival for patients with prostate cancer in 2018, indicated in blue-gradient colors. (b) A positive correlation pattern between the survival of the patients diagnosed in 2010-2014 and the HDI value in $2018(r=0.669, p<0.0001$, slope $=108.4)$. (c) Correlation between national MIR and survival of prostate cancer in $2018(r=-0.749, p<0.0001$, slope $=-72.97)$. 
a)
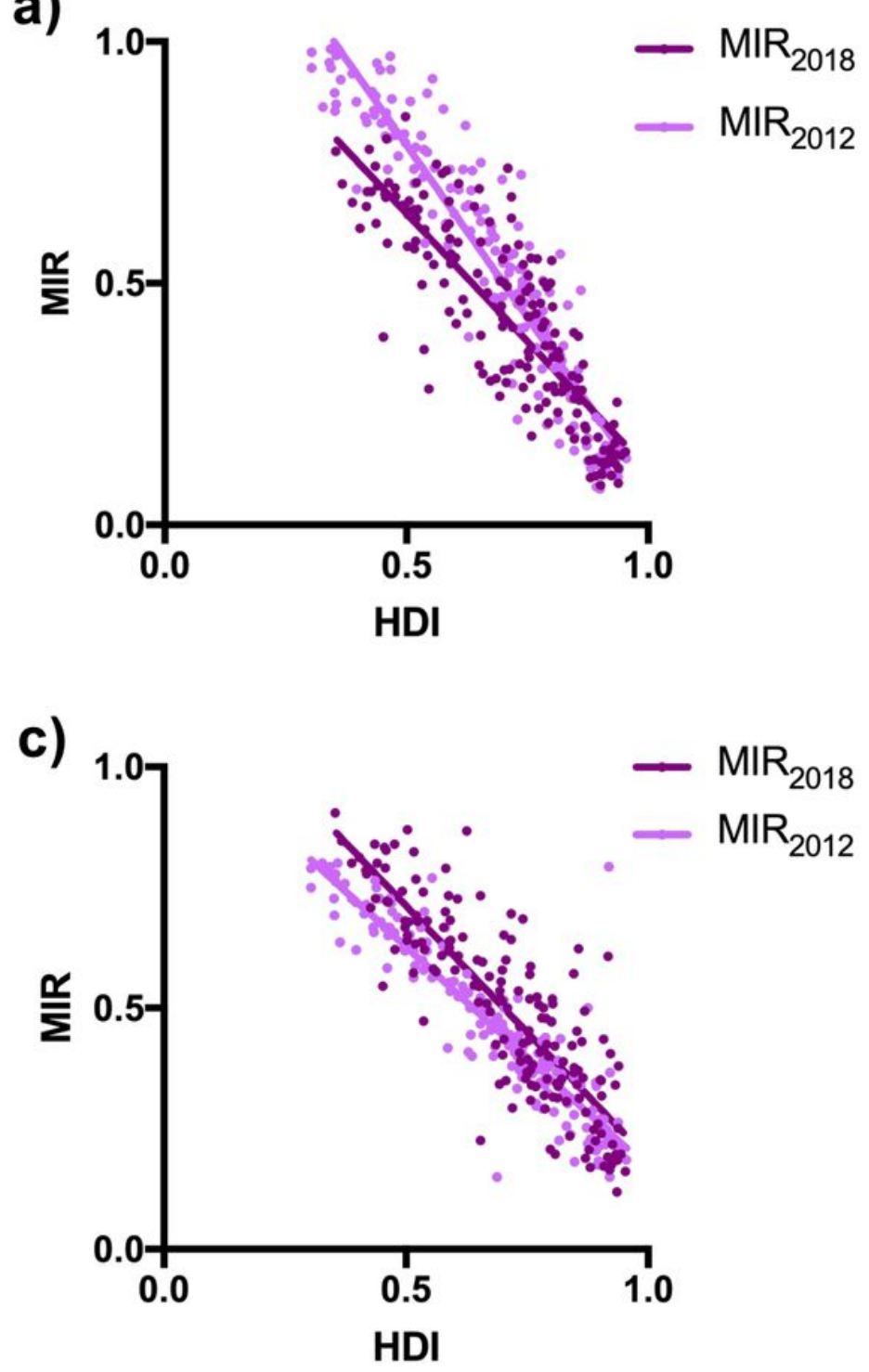

b)

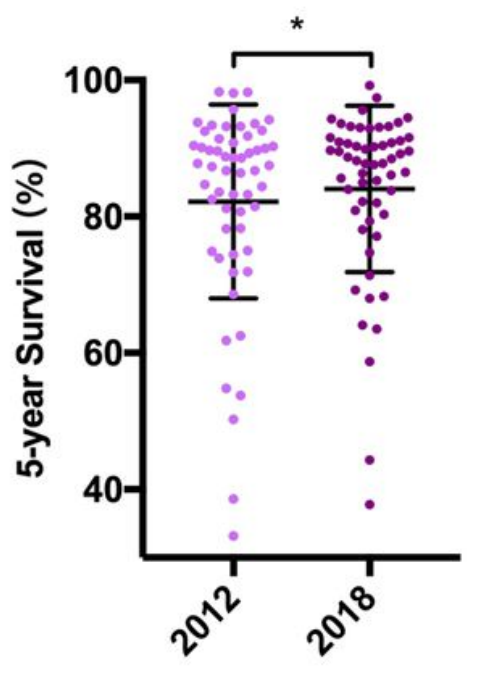

\section{Figure 5}

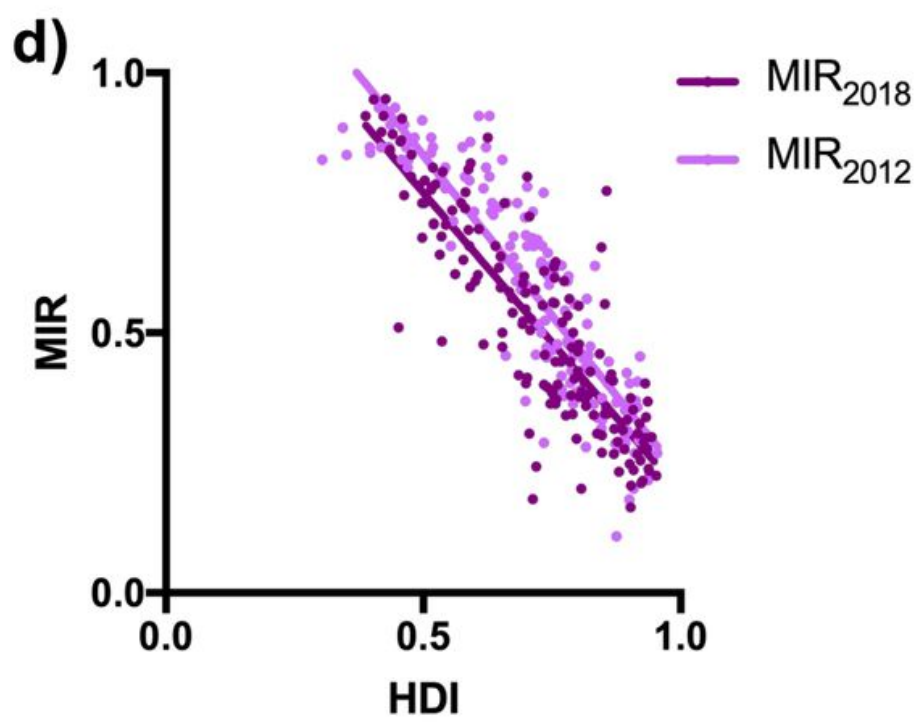

Urologic cancer outcomes and its trend from 2012 to 2018. Transition of the correlation patterns of (a) prostate cancer MIR to national HDI from 2012 (light purple, $r=-0.617, p<0.0001$ ) to 2018 (dark purple, $r$ $=-0.548, p<0.0001$ ), (c) bladder cancer from 2012 () to 2018 (), as well as (d) kidney cancer from 2012 () to 2018 , showing a declining tendency of MIRs within the decade. (b) Significant increase in overall survival rates in 57 overlapping countries from 2012 (light purple) to 2018 (dark purple). ${ }^{*} p<0.05$, paired t-test.

\section{Supplementary Files}

This is a list of supplementary files associated with this preprint. Click to download.

- Supplementary.docx 
- FS.jpg

Page 20/20 